\title{
Adrenaline Load of the Suprarenal Glands of Rabbits in Histamine Poisoning.
}

\author{
By \\ Tatuzi Suzuki. \\ (敛 木 達二) \\ (From the Physiological Laboratory of Prof. Y. Satake, \\ Tohoku University, Sendai.) \\ (Received for publication, April 21, 1951)
}

On the glycemic action of histamine, an interesting fact -was found by Satow 1" in our laboratory. "In rabbits, hyperglycemia is caused by the intravenous injection of histamine in a dose of $0.4-0.5 \mathrm{mg}$ per $\mathrm{kg}$ rapidly (in 5-20 seconds). On the contrary, blood sugar decreases, when the same dose of histamine is injected slowly (in 1-1.5 minutes). This was confirmed in rabbits also by Takita ${ }^{21}$ in our laboratory. Therefore it seemed to be of interest to know how acts the histamine, adminstrated rapidly or slowly, on the adrenaline load of the suprarenals.

As regards the influence of histamine poisoning upon the adrenaline load of the suprarenal glands some papers ${ }^{8)}$ dealt with.

\section{Method.}

Healthy rabbits were used. Histamine phosphate ("Takeda") was injected in a following way.

(a) $0.5 \mathrm{mg}$ histamine per $\mathrm{kg}$ of body weight was injected intravenously as a $0.1 \%$ solution in 10 seconds.

(b) Histamine in a same dose was injected intravenously in 60 seconds.

(c) $20 \mathrm{mg}$ histamine per $\mathrm{kg}$ was injected subcutaneously as a $1 \%$ solution.

In some cases the animal died after histamine injection. In these cases the suprarenal glands were extirpated soon after the death. In other cases, 30 minutes after intravenous injection or 120 minutes after the subcutaneous injection, after killing the animal by a blow on a neck, the surparenals were removed. For the estimation of adrenaline in the suprarenals, the corrosive sublimate method of Suto-Kojimat) was used, taking Adrenaline chloride ("Sankyo") as a standard. The actual concentration of adrenaline was determined by the method of Kodama. ${ }^{5}$ )

\section{Results.}

The adrenaline load of suprarenal glands in 9. normal rabbits was determined as a control of the present investigations. The results were 
TABLE I.

Adrenaline Load in Suprarenal Glands of Normal Rabbits.

\begin{tabular}{|c|c|c|c|c|c|c|c|c|c|c|}
\hline \multirow{3}{*}{ No. } & \multirow{3}{*}{ Date } & \multirow{3}{*}{$\begin{array}{l}\text { Body } \\
\text { weight } \\
\text { (kg) } \\
\text { and } \\
\text { sex }\end{array}$} & \multirow{2}{*}{\multicolumn{2}{|c|}{$\begin{array}{l}\text { Weight of } \\
\text { suprarenal } \\
\text { gland (g) }\end{array}$}} & \multicolumn{6}{|c|}{ Adrenaline load (mg) } \\
\hline & & & & & \multicolumn{2}{|c|}{ total quantity } & \multicolumn{2}{|c|}{ per $g$ gland } & \multicolumn{2}{|c|}{$\begin{array}{c}\text { per kg of } \\
\text { body weight }\end{array}$} \\
\hline & & & $\mathbf{R}$ & $\mathrm{L}$ & $\mathbf{R}$ & $\mathbf{L}$ & $\mathbf{R}$ & $\mathbf{L}$ & $\mathbf{R}$ & L \\
\hline 1 & 2.X. $\quad ' 42$ & $1.53 \%$ & 0.115 & 0.126 & 0.075 & 0.071 & 0.65 & 0.56 & 0.049 & 0.046 \\
\hline 2 & 7. X. 142 & $2.11 \delta$ & 0.177 & 0.198 & 0.07 & 0.074 & 0.40 & 0.37 & 0.034 & 0.035 \\
\hline 3 & 22. $\mathrm{X} . \quad 42$ & 1.73 우 & 0.080 & 0.10 & 0.04 & 0.045 & 0.54 & 0.43 & 0.025 & 0.026 \\
\hline 4 & 12. XI. ' 42 & $2.56 \delta$ & 0.385 & 0.385 & 0.126 & 0.109 & 0.33 & 0.28 & 0.049 & 0.043 \\
\hline 5 & 29. IX. ' 43 & 1.74 ㅇ & 0.164 & & 0.0 & 0.066 & 0.41 & 0.40 & 0.039 & 0.038 \\
\hline 6 & 39. IX.' 43 & 1.90 우 & 0.276 & 0.281 & 0.11 & 0.120 & 0.40 & 0.43 & 0.058 & 0.063 \\
\hline 7 & 12. X. ' 43 & 1.65 우 & 0.091 & 0.104 & 0.061 & 0.063 & 0.67 & 0.61 & 0.037 & 0.038 \\
\hline 8 & 22. XII.'43 & 1.73 우 & 0.109 & 0.124 & 0.072 . & 0.068 & 0.66 & 0.55 & 0.042 & 0.039 \\
\hline 9 & 25. XII.'43 & $1.26 \%$ & 0.103 & 0.109 & 0.050 & 0.050 & 0.49 & 0.46 & 0.040 & 0.040 \\
\hline \multicolumn{2}{|c|}{ Average } & 1.80 & 0.167 & 0.177 & 0.075 & 0.074 & 0.51 & 0.45 & 0.041 & 0.041 \\
\hline
\end{tabular}

displayed in Tab. I. In these normal rabbits the adrenaline load of suprarenals per gland was in an average value $0.075 \mathrm{mg}$ for the right gland and $0.074 \mathrm{mg}$ for the left gland, the adrenaline load per $\mathrm{kg}$ of body weight was in a mean $0.041 \mathrm{mg}$ for the suprarenals of each sides and adrenaline per $\mathrm{g}$ of gland was in a mean value $0.51 \mathrm{mg}$ for the right gland and $0.45 \mathrm{mg}$ for the left gland. These values coincide nearly with the value reported in the statistical studies of $\mathrm{H}$. Sato on the adrenaline load of suprarenal glands of 617 normal rabbits, only the adrenaline load per $\mathrm{g}$ of gland of the present experiments is somewhat smaller than that of H. Sato.

The chief experiments were performed on 23 rabbits. The results were presented in Tab. II.

In 8 rabbits, histamine in a dose of $0.5 \mathrm{mg}$ per $\mathrm{kg}$ of body weight was injected intravenously in 10 seconds. Soon after the injection the intensive convulsions took place in 4 rabbits, and 3 rabbits out of them died eventually. In other 4 rabbits the convulsions did not occur, and only the tachycardia and depression were observed. In averaging the values in these 8 rabbits, the adrenaline load per gland was $0.080 \mathrm{mg}$ for the right gland and $0.079 \mathrm{mg}$ for the left gland, adrenaline per $\mathrm{kg}$ of body weight was $0.043 \mathrm{mg}$ for the suprarenals of each sides, and adrenaline per $\mathrm{g}$ of gland was $0.49 \mathrm{mg}$ for the right suprarenals and $0.44 \mathrm{mg}$ for the left suprarenals.

In other 8 rabbits the same dose of histamine was injected intravenously in 60 seconds. Only one rabbit out of them died after a occurrence of intensive convulsions. In other rabbits the convulsions were 
TABLE II.

Adrenaline Load in Suprarenal Glands of Rabbits in Histamine Poisoning.

\begin{tabular}{|c|c|c|c|c|c|c|c|c|c|c|c|}
\hline \multirow{3}{*}{ No. } & \multirow{3}{*}{ Date } & \multirow{3}{*}{ 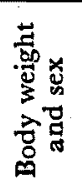 } & \multirow{2}{*}{\multicolumn{2}{|c|}{$\begin{array}{l}\text { Weight of } \\
\text { suprarenal } \\
\text { gland } \\
\text { (g) }\end{array}$}} & \multicolumn{6}{|c|}{ Adrenaline load (mg) } & \multirow{3}{*}{ 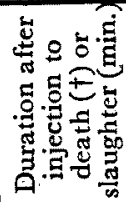 } \\
\hline & & & & & & & & & & $\begin{array}{l}\text { of } \\
\text { eight }\end{array}$ & \\
\hline & & & $\mathbf{R}$ & $\mathbf{L}$ & $\mathbf{R}$ & $\mathbf{L}$ & $\mathbf{R}$ & $\mathbf{L}$ & $\mathbf{R}$ & $\mathbf{L}$ & \\
\hline
\end{tabular}

(A) Rapid intravenous injection of histamine $(0.5 \mathrm{mg}$ per $\mathrm{kg})$. Duration of injection $10 \mathrm{sec}$.

\begin{tabular}{|c|c|c|c|c|c|c|c|c|c|c|}
\hline & 14. IX 142 & 2.53 ช & 0.296 & 0.297 & 0.074 & 0.070 & 0.25 & 0.24 & 0.029 & 0.028 \\
\hline & 18. IX. 142 & $1.67 \delta$ & 0.199 & 0.174 & 0.094 & 0.083 & 0.47 & 0.48 & 0.056 & 0.050 \\
\hline & 18. IX. 142 & 2.06 ㅇ & 0.182 & 0.184 & 0.054 & 0.050 & 0.30 & 0.27 & 0.026 & 0.024 \\
\hline & 21. IX: 42 & 1.86 우 & 0.107 & 0.124 & 0.117 & 0.113 & 0.99 & 0.91 & 0.063 & 0.061 \\
\hline & 21. IX. 42 & 1.61 ㅇ․ & 0.230 & 0.245 & 0.111 & 0.114 & 0.48 & 0.47 & 0.069 & 0.071 \\
\hline & 25. IX $/ 42$ & 1.58 。 & 0.118 & 0.131 & 0.091 & 0.093 & 0.77 & 0.71 & 0.058 & 0.059 \\
\hline & 28. IX. $/ 42$ & 1.83 우 & 0.119 & 0.155 & 0.034 & 0.040 & 0.29 & 0.26 & 0.019 & 0.022 \\
\hline & 28. IX 42 & $2.45 \delta$ & 0.276 & 0.313 & 0.063 & 0.065 & 0.23 & 0.21 & 0.026 & 0.027 \\
\hline & & & 0.191 & 0.203 & 080 & 0.079 & 0.49 & 0.44 & 0.043 & 0.043 \\
\hline
\end{tabular}

(B) Slow intravenous injection of histamine $(0.5 \mathrm{mg}$ per $\mathrm{kg})$. Duration of injection $60 \mathrm{sec}$.

\begin{tabular}{|c|c|c|c|c|c|c|c|c|c|c|c|}
\hline 9 & 11. XII.'43 & 1.53 。 & 0.111 & 0.166 & 0.073 & 0.065 & 0.66 & 0.39 & 0.048 & 0.043 & 30 \\
\hline 10 & 11. XII.'43 & 1.70 古 & 0.272 & 0.282 & 0.059 & 0.065 & 0.22 & 0.23 & 0.035 & 0.038 & 30 \\
\hline 11 & 12. XII.'43 & 2.06 今 & 0.276 & 0.278 & 0.084 & 0.091 & 0.30 & 0.33 & 0.041 & 0.044 & 30 \\
\hline 12 & 12. XII.'43 & 2.15 우 & 0.224 & 0.277 & 0.068 & 0.077 & 0.30 & 0.28 & 0.032 & 0.036 & $6 \dagger$ \\
\hline 13 & 22. XII. ${ }^{\prime} 43$ & 1.74 今 & 0.189 & 0.250 & 0.151 & 0.155 & 0.80 & 0.62 & 0.087 & 0.089 & 30 \\
\hline 14 & 24. XII.'43 & 1.60 우 & 0.110 & 0.114 & 0.057 & 0.055 & 0.52 & 0.48 & 0.036 & 0.034 & 30 \\
\hline 15 & 24. XII. 43 & 1.62 우 & 0.098 & 0.093 & 0.054 & 0.050 & 0.55 & 0.54 & 0.033 & 0.031 & 30 \\
\hline 16 & 25. XII.' 43 & 1.90 。 & 0.172 & 0.213 & 0.074 & 0.056 & 0.43 & 0.26 & 0.039 & 0.030 & 30 \\
\hline \multicolumn{2}{|c|}{ Average } & 1.79 & 0.182 & 0.209 & 0.078 & 0.077 & 0.47 & 0.39 & 0.044 & 0.043 & \\
\hline
\end{tabular}

(C) Subcutaneous administration of histamine (20 $\mathrm{mg}$ per $\mathrm{kg}$ ).

\begin{tabular}{|c|c|c|c|c|c|c|c|c|c|c|}
\hline 17 & 25. IX. $' 42$ & 1.66 우 & 0.105 & 0.101 & 0.052 & 0.050 & 0.50 & 0.50 & 0.031 & 0.030 \\
\hline 8 & 22. X. ' 42 & $1.81 \%$ & 0.134 & 0.136 & 0.034 & 0.027 & 0.25 & 0.20 & 0.019 & 0.015 \\
\hline 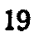 & 29. X. $\quad 42$ & 1.77 \& & 0.116 & 0.126 & 0.062 & 0.061 & 0.53 & 0.48 & 0.035 & 0.034 \\
\hline 0 & 7. X. 143 & 1.84 우 & 0.141 & 0.174 & 0.069 & 0.067 & 0.49 & 0.39 & 0.038 & 0.036 \\
\hline 1 & 12. X. $\quad 43$ & 1.91 ㅇ & 0.271 & 0.302 & 0.075 & 0.071 & 0.28 & 0.24 & 0.039 & 0.037 \\
\hline 2 & 18. XII.' 43 & 2.18 今 & 0.263 & 0.331 & 0.061 & 0.072 & 0.23 & 0.22 & 0.028 & 0.033 \\
\hline & 25. XII:'43 & 1.93 ธิ & 0.285 & 0.322 & 0.070 & 0.067 & 0.25 & 0.21 & 0.036 & 0.035 \\
\hline \multicolumn{2}{|c|}{ Average } & 1.87 & 0.188 & 0.213 & 0.060 & 0.059 & 0.36 & 0.32 & 0.032 & 0.031 \\
\hline
\end{tabular}


not observed. The rate of heart beat increased definitely. The mean value of the adrenaline load of the suprarenals in these rabbits was 0.078 $\mathrm{mg}$ and $0.077 \mathrm{mg}$ per gland for the right and the left glands respectively; and $0.044 \mathrm{mg}$ per $\mathrm{kg}$ of body weight for the right gland and $0.043 \mathrm{mg}$ per $\mathrm{kg}$ for the left gland, and $0.47 \mathrm{mg}$ per $\mathrm{g}$ of gland for the right suprarenals and $0.39 \mathrm{mg}$ for the left.

Thus in our experiments non-effect of histamine was observed, which was injected rapidly or slowly in a dose of $0.5 \mathrm{mg}$ per $\mathrm{kg}$ upon the adrenaline load of the suprarenal glands.

In another series of experiments, histamine was injected subcutaneously in a dose of $20 \mathrm{mg}$ per $\mathrm{kg}$ in 7 rabbits. This dose of histamine is, according to the report of Hirano ${ }^{71}$ in our laboratory, about double as much as the maximum non-lethal dose in rabbits and in fact 3 rabbits out of 5 in his experiment died after subcutaneous injection of histamine in a dose of $20 \mathrm{mg}$ per $\mathrm{kg}$. Nevertheless in the present experiments no rabbit died after application of the same dose of histamine. The rate of heart beat increased markedly. The depression and urination were often observed. The adrenaline load of the surparenal glands in these 7 rabbits was on an average $0.060 \mathrm{mg}$ for the right gland and $0.059 \mathrm{mg}$ for the left gland. Reckoning the body weight or the weight of gland, they are in a mean value $0.032 \mathrm{mg}$ per $\mathrm{kg}$ of body weight in the right gland and $0.031 \mathrm{mg}$ per $\mathrm{kg}$ in the left gland, $0.36 \mathrm{mg}$ per $\mathrm{g}$ of gland in the right gland and $0.32 \mathrm{mg}$ per $\mathrm{g}$ of gland in the left gland.

Comparing these values with those of the control experiments, it is clear that the subcutaneous application of histamine in a dose of $20 \mathrm{mg}$ per $\mathrm{kg}$ of body weight causes a reduction of adrenaline load in the suprarenal gland.

In this connection we should recall the report of Z. Kanowokas) on the peptone poisoning. When the animal does not die within a short period and the symptoms of poisoning continue for a certain length of time, the adrenaline load decreases. On the other hand, when the poisoning symptom is severe and the animal dies in a short period, adrenaline load of the suprarenals is not reduced.

\section{Summary.}

From the evidence reported by Satow that the glycemic action of histamine is quite different in using the different manner of applications, the interest was evoked, and the present studies were undertaken to know whether the similar evidence can be found or not concerning the influence of histamine upon the adrenaline load of the suprarenal gland.

Rabbits were used. The adrenaline load of the suprarenal glands was estimated by the corrosive sublimate method of Suto-Kojima. His- 
tamine was injected intravenously in a dose of $0.5 \mathrm{mg}$ per $\mathrm{kg}$ of body weight in 10 seconds or in 60 seconds. Some rabbits died several minutes after histamine injection and others were able to recover. In the former the suprarenals were removed soon after death and in the latter it was removed 30 minutes after injection. In these experiments we could not find any definite alteration of adrenaline load after histamine. Subcutaneous injection of histamine in a dose of $20 \mathrm{mg}$ per $\mathrm{kg}$ was also applied. In this series of experiments the reduction of adrenaline load was observed.

\section{References.}

1 Satow, Tohoku J. Exp. Med., 1938, 32, 239.

2 Takita, ibid., 1950, 53, 145.

3 Elliott, J. Physiol., 1912, 44, 387 f. (Cats, cat blood pressure, adrenaline load was reduced.); Oikawa, Tohoku J. Exp. Med., 1931, 18, 39 f. (Rabbits, Suto-Kojima, histamine 1.2 mg or $2.0 \mathrm{mg}$ i. v., adrenaline load was reduced.); Kishima, Nippon Yakubutu. Z., 1937, 24, $62 \mathrm{P}$. (Dog, Suto-Inouye, histamine $30 \mathrm{mg}$ per $\mathrm{kg} \mathrm{s} . \mathrm{c}$. or $10 \mathrm{mg}$ per $\mathrm{kg}$ daily s. c., adrenaline load was reduced.); Jap. J. Med. Sci., Pharmacol, 1937, 10, 64. (The same as above. However as regards the number of dogs and the mean values of adrenaline load, it is somewhat different from that of the Japanese paper.); Koref and Rivera, Wiener med. Wschr., 1937, 87, 18 4, (Guinea-pigs, Folin-Cannon-Denis, histamine $1 \mathrm{mg}$ per $\mathrm{kg}$ i. v. or $5 \mathrm{mg}$ per $\mathrm{kg} \mathrm{s}$. c., adrenaline load per $\mathrm{g}$ of gland and per $\mathrm{kg}$ of body weight were reduced.)

4 Kojima, T., Tohoku J. Exp. Med., 1928, 10, 281.

5 Kodama, J. Biochem., 1922, 1, 281.

6 Sato, H., Iwate Igk. Z., 1939-40, 4, 242.

7 Hirano, Tohoku J. Exp. Med., 1939, 37, 322.

8 Kanowoka, Z., ibid., 1935, 25, 244. 